\title{
Axiological Features of the Concept \\ CHARM / CHARIVNIST in the English and Ukrainian Languages (Contrastive Aspect)
}

\section{Ціннісні ознаки концепту CHARM / ЧAPIBHICTЬ в англійській та українській мовах (контрастивний аспект)}

\author{
Yuliia Tomchakovska \\ Ph.D. in Philology, \\ Associate Professor
}

\section{Юлія Томчаковська}

кандидат філологічних наук, доцент

$$
\begin{gathered}
\text { E-mail: yuliya.tomchakovskaya@gmail.com } \\
\text { orcid.org/0000-0003-0117-2704 } \\
\text { Researcher ID: H-9451-2018 }
\end{gathered}
$$

\author{
National University \\ "Odessa Academy of Law» \\ 23, Fontanskaya doroha Str., \\ Odessa, Ukraine, 65000
}

Національний університет

«Одеська юридична академія»

$\triangle$ вул. Фонтанська дорога, 23, м. Одеса, Україна, 65000

Original manuscript received February 15, 2018

Revised manuscript accepted October 12, 2018

\begin{abstract}
The article is devoted to the study of the linguo-cultural concept CHARM / CHARIVNIST in the English and Ukrainian languages. The aim of the work is to identify axiological characteristics of the CHARM / CHARIVNIST concept in English and Ukrainian Internet discourses on the basis of the textrecommendations "How to be Charming" / "Yak staty charivnoyu», etc. The object of the research is concept CHARM / CHARIVNIST as an aesthetic component of the English and Ukrainian world images; the subject - similarity, difference and contrast in the ways of verbalization of concept CHARM / CHARIVNIST in the English and Ukrainian languages and peculiarities of the discourse realization of the given concept in corresponding linguocultures.
\end{abstract}


Internal and external characteristics of the formation of the image of the CHARMING PERSON have been singled out. Internal features are semantic indicators of the concept CHARM / CHARIVNIST. External features are physical indicators of the concept and include mimic, eye contact, voice and touching features. For English-speaking recipients, such axiological feature as SELFDEVELOPMENT or DEVELOPMENT OF PERSONALITY is important, which is foregrounded through its components: self-esteem, self-confidence, self-control, "simply-be-yourself» that appear first of all in the body language, for example, FACE (satisfaction, expressive), SMILE (genuine, big, friendly, sincerely), EYE CONTACT (direct), TOUCHING (light), HANDSHAKE (firm), and VOICE (boldness, confident, gentle, peaceful, direct). The following axiological features of the concept of CHARIVNIST in the Ukrainian texts-recommendations have been singled out: sincerity, cheerfulness, originality, with physical characteristics (eyes, voice, smile) serving as "external indicators of the charming inner world", for example, eyes as a mirror of the soul, a smile as a generator of positive fluids, etc. It has been proved that the discoursive feature of SELFDEVELOPMENT of the English concept CHARM is contrasting. It has been established that such discoursive feature of the Ukrainian concept CHARIVNIST as ORIGINALITY is contrasting, and the discoursive features CONFIDENCE and VPEVNENIST are integral to the two concepts.

Key words: concept, axiological features, Internet discourse, charm, charivnist.

\section{Вступ}

Необхідність дослідження когнітивної природи чарівності визначається тим, що це поняття давно зустрічається і широко застосовується у різних професійних сферах, таких, як публічна діяльність, менеджмент, суспільна взаємодія, реклама, кінематограф, шоу-бізнес тощо, не маючи, проте, визначеного чіткого змісту й емпірично виявлених характеристик для кожної із вказаних професійних сфер.

Складність виявлення поняття «чарівність» зумовила різні підходи до його вивчення. У царині психології масової комунікації аналізу підлягають, перш за все, риси привабливого, симпатичного, популярного й ідеального комунікатора (диктора, ведучого, шоумена тощо) (Агеичева, 2007; Müller, 2012; Ogiermann, 2009; SpencerOatey, 2008). 3 позицій лінгвокультурології та лінгвоконцептології чарівність розглядають як лінгвокультурний концепт (Карасик, 2002), який по-різному тлумачиться у різних культурах. Пошук паралелей i розходжень у когнітивно-дискурсивній 
реконструкції лінгвокультурних концептів (Pinker, 2013) входить до загальної парадигми сучасних типологічних, зіставних та контрастивних студій і спрямований на визначення спільних та відмінних характеристик мовного освоєння дійсності людиною в споріднених i неблизькоспоріднених мовах та його втілення у різних типах дискурсу (Forker, 2016; Hampton \& Moss, 2003; Suomela-Salmi, 2009).

Актуальність пропонованої розвідки визначається ii відповідністю загальному спрямуванню сучасної лінгвістики на вивчення лінгвокультурних концептів як колективних змістовних ментальних утворень, що фіксують своєрідність відповідної культури (Shipp \& alt., 2018), а також важливістю отримання науково обгрунтованих даних стосовно чарівності як загального психологічного й естетичного явища, визначення ціннісного складника концепту CHARM/ЧАРIBHICТЬ як естетичного поняття в англомовній та україномовній картинах світу.

\section{Методи та методики дослідження}

Під час лінгвістичного аналізу використано загальнонаукові методи (аналіз, порівняння) та спеціальні лінгвістичні методи: концептуальний аналіз - для окреслення ціннісного складника досліджуваного концепту, контекстуально-інтерпретаційний аналіз - для тлумачення реалізації когнітивних ознак вербалізованих концептів CHARM/ЧАРІBНICТЬ в англомовній та україномовній лінгвокультурах; зіставний (контрастивний) аналіз - для двостороннього зіставлення засобів вербалізації концептів CHARM / ЧАРІВНІСТЬ в англійській та українській мовах для виявлення контрастів його адаптації у кожній із неблизькоспоріднених лінгвокультур; кількісний аналіз - для визначення частотності розподілу даних в окремих підвибірках лінгвального матеріалу.

Застосування комплексу зазначених методів дозволило організувати дане дослідження наступним чином. Як об'єкт дослідження було обрано концепт СНARM / ЧАРІВНІСТЬ як естетичний компонент англомовної та україномовної картин світу. Предметом аналізу слугували подібності, відмінності та контрасти у способах вербалізації концепту CHARM / ЧАРІВНICТЬ в 
англійській та українській мовах і специфіка дискурсивного втілення даного концепту у відповідних лінгвокультурах.

Матеріалом дослідження слугувала вибірка 336 текстів сучасного Інтернет-дискурсу (тексти-рекомендації (укр. поради) за типом «How to be» / Як бути...» або «The ways of...» / «Способи, як бути...») обсягом 15000 словоформ для кожної мови, які обиралися за наявністю у заголовку чи власне самому тексті лексичних одиниць, що номінують досліджуваний концепт: charm / charming / чарівність/чарівний.

\section{Результати дослідження}

Під концептом розуміємо ментальний комплекс, певним чином організовану різносубстратну одиницю знань, яка $\epsilon$ включеною до свідомості людини та іiі колективне несвідоме (Селіванова, 2006: 112; Taylor \& alt., 2011). Детальний опис структури концепту пропонує М.В. Піменова, яка виділяє в ній шість класів ознак: мотивуючі, понятійні, образні, ціннісні, оцінні і символічні (Пименова, 2007: 17). У свою чергу, В.I. Карасик, розуміючи концепт як багатовимірне ментальне утворення, виділяє три істотних ознаки концепту: понятійну, образну і ціннісну складові (Карасик, 2009: 183).

Незважаючи на різну кількість виокремлених ознак, учені погоджуються у визначенні ціннісних ознак в структурі концепту, які підкреслюють особливу значущість відповідного фрагмента світу для носіїв певної мови, ціннісне ставлення людини до того чи іншого об'єкту, поняття (Пименова, 2007: 83).

Мета даної розвідки полягає у виявленні ціннісних характеристик концепту CHARM / ЧАРІВНІСТЬ в англомовній та україномовній лінгвокультурах. Мовленнєве втілення концепту CHARM в англомовному Інтернет-дискурсі досліджено на матеріалі текстів-рекомендацій, які носять прагматичний характер i навчають читачів, як сформувати свій позитивний імідж в повсякденній комунікації, професійній діяльності та використовувати ціннісні ознаки даного концепту з маніпулятивною метою. За своєю жанровою спрямованістю тексти-рекомендації характеризуються великою різноманітністю і відрізняються певною лінгвокультурною специфікою. 
Ціннісні ознаки кониеепту CHАRM / ЧАРІВНICTБ в англійській...

Структура проаналізованих текстів-рекомендацій в англомовному інтернет-дискурсі характеризується рядом спільних рис, які полягають в «подачі» ознаки за допомогою (1) iii прямої номінації у вигляді коротких бездієслівних конструкцій (напр.: «Contagious Laugh», «Vocal Expression of Emotion», «Expressive Face» / «Запам'ятовування імен», «Зацікавленість», «Справжність») або (2) iї інтеграції в імперативні конструкції різного типу (напр.: Take the positive spin! Fix your goal! Smile sincerely! / Завжди будь чесним, ввічливим і природним! Умій цікаво базікати про все! Усміхайся!), які вводять подальше тлумачення ознаки і як би «нанизують» пояснення, як тренувати і застосовувати iii на практиці (напр.: Take the positive spin! $\rightarrow$ [People want to be around other positive people not complainers or those who always take the negative spin. If you can see the positive in situations - even bettertake action towards making things more positive then you will be seen as someone of high social importance becoming much more attractive to those around you]. Обсяг тренувальної рекомендації також може бути різним і варіюватися від трьох до десяти пропозицій.

Оскільки основною метою цього дослідження є реконструкція концепту ЧАРІВНІСТЬ в англійській і українській лінгвокультурах, ми залишаємо за межами аналізу в даній роботи особливості маніпулятивних i навчальних тактик i стратегій, характер рекомендацій (експліцитні / імпліцитні, прямі / непрямі), використання цитат історичних і сучасних відомих особистостей як опору на авторитет в своїх аргументативних прийомах і т. д.

Перейдемо до розгляду ціннісних ознак створення іміджу CHARMING PERSON в англомовних текстах.

Внутрішні ціннісні ознаки CHARMING PERSON $\epsilon$ змістовними «індикаторами» концепту CHARM і проявляються через домінуючу ознаку SELF-DEVELOPMENT або DEVELOPMENT OF PERSONALITY, наприклад, «For the development of personality, in other words, for self-development, we can take some measures that will transform us into great human beings». Ознака SELF-DEVELOPMENT презентується концептами:

1. GOAL, AIM, MENTAL INSPIRATION, наприклад, «Maybe we are busy or tired, or sometimes do not feel like working. In this case, our main problem is the lack of a definite aim. So we have to select and fix a goal before we start to work»; "Aim always gives 
mental inspiration and strengthens your confidence-level. However, the researchers have observed that if the aim is too flexible, it is never successful».

2. TIME, наприклад, «Start working with enough time in your hand. Those, who take time to start a work, are, in one sense, too much optimistic. They think that though they have started late, they will be able to finish it in time»; "To answer unnecessary telephone calls, use the most unproductive time of the day, for example, before the lunchtime or before you go to the office in the afternoon».

3. MEDITATION, наприклад, «Meditate again in the morning. Make your work schedule for the whole day. Start your day's work with new inspiration».

Ознака SELF-DEVELOPMENT актуалізується в таких складових, як «self-esteem / самоповага», «self-confidence / впевненість в собі», «self-control / самовладання, володіння собою», «simplybe-yourself / просто-будь-собою». Так, SELF-ESTEEM має бути, перш за все, здоровим (healthy, good), наприклад, «Yоu may have noticed that people with a magnetic personality are most often calm and composed. This comes from healthy self-esteem»; "Care about your appearance, because looking better helps with self-esteem (хороший внешний вид помогает здоровому самоуважению) and you must have a good self-esteem and confidence».

Ознака SELF-CONFIDENCE, SELF-LOVE характеризується як quiet, inspiring, convincing, наприклад, «Exude a quiet self-confidence», «Self-love, self-confidence and authenticity are the foundational elements of attractiveness». Потрібно зазначити, що лексична одиниця selfconfident в англомовній культурі має позитивну конотацію.

Ознаку SELF-CONTROL необхідно «включати» для контролю над негативними емоціями, наприклад, «Control your anger: look for the reasons behind your anger. Take realistic measures to sweep off these reasons. Your anger and excitement will drop down soon»; "Control your tone of voice. Your voice should be gentle and peaceful, yet direct. Articulate your words clearly and project your voice. Practice giving compliments into a recorder and play it back. Does your voice sound sincere?».

Прикладом актуалізації ознаки «SIMPLY-BE-YOURSELF» $є$ : «Do not concern yourself with what others think about you. You can not control what they think about you anyway, so do not worry about 
making a good impression. Simply be yourself. People appreciate your honesty when you always show your true colors».

Перейдемо до аналізу зовнішніх ознак створення іміджу CHARMING PERSON у досліджених текстах.

В англомовній лінгвокультурі для розвитку іміджу «charming person» необхідно враховувати, що BODY LANGUAGE грає величезну роль в транслювання чарівності, впевненості, наприклад: «Body language can go a long way in making people think you are confident».

Найважливішими в іміджі чарівної людини є такі ознаки, що вкладаються в меседжі проаналізованих текстів-рекомендацій:

(1) мімічні: FACE в цілому, яке повинно бути виразним (expressive) (1) "It's also related to having an expressive face, in that the more your audience can read in your body language, the more they grasp your meaning and enjoy your company», і може висловлювати різні почуття, наприклад satisfaction (2) Your face will show your satisfaction, chest uplifted», pride (3) «So you feel proud and your face glows in pride» i SMILE genuine, big, friendly, sincerely, наприклад, «A smile is always something good, because it shows you have a nice personality and helps you feel okay»;

(2) окулесичні: EYE CONTACT, наприклад: (1) «Looking at people directly in the eyes gives you a certain hold over them»; (2) «Keep eye contact throughout the conversation. No matter what you're talking about, holding the person's eyes will make you seem more charming»;

(3) фонаційні: VOICE (confident, gentle, peaceful, direct, sincere), наприклад: (1) «A lively, expressive voice is one of the most powerful instruments in the world, especially when it's resonant and sparkles with changes of pitch, speed, and volume», (2) «Your voice should be gentle and peaceful, yet direct»;

(4) гаптичні: TOUCHING (light), наприклад: «During the course of the conversation, it may be appropriate to use light touching to keep it moving. You can lightly touch the person's shoulder». I HANDSHAKE (firm), наприклад: «When you meet someone, give a firm handshake and look the other person in the eye»;

Внутрішні ціннісні ознаки ЧАРІВНОЇ ЛЮДИНИ, які виступають в ролі змістовних «індикаторів» концепту ЧАРІВНІСТЬ в українській мові, пов'язані, перш за все, з ознаками щииість, 
душевність, жіттєрадісність, веселість, які є типовими душевними цінностями українців.

Ознаки ЩИРІСТЬ, ДУШЕВНІСТЬ презентуються через концепт «широка душа» наприклад: «I, мабуть, найголовніше будьте природними. Вся сила, вся енергія повинна йти зсередини и буті справжньою. Душевність и щуирість високо цінуються в кожної особистості»; «Для хорошого спілкування, необхідно самій бути з широкою душею. У иее поняття вкладаються такі якості, як відкритість, щзирість, щзедрість. Почни з того, щзо під час перерви почастуй колег пирогом власної випічки або чукерками».

Ознаки ЖІТТЕРАДІСНІСТЬ, ВЕСЕЛІСТЬ актуалізуються через концепти «душа компанії», «центр тяжіння компанії», «зірка компанії», наприклад: «Приваблива людина завжди знаходиться в оточенні друзів. Саме з нею колеги хочуть перекусити в обідню перерву, вона $\epsilon$ душею компанії та бажана в будь-якому домі»; «Найважливішою характеристикою чарівності $\epsilon$ емочійна привабливість людини. Центром тяжіння компанї стає не найкрасивіший, а хто? - Самий веселий $і$ життєрадісний чоловік».

Ознака ТЯЖІННЯ, ПРИТЯГАННЯ реалізуються також через концепт «магніт», наприклад: «Привабливі жінки, ніби магніт, притягують до себе людей, причому не тільки чоловіків, а й жінок. Під чарівність привабливої особи изілком може потрапити й інша представниияя слабкої статі. Люди тягнуться до того тепла, затишку, який буквально виходить від чарівних $i$ привабливих жінок»; «Внутрішня чарівність - великий магніт. Але як будь-яке складне $i$ чудове властивість, чарівність можна не тільки розвинути, але $і$ втратити. I як часто в гонитві за ідеальними розмірами пропориій свого тіла або модними нарядами ми забуваємо про свої виключно індивідуальних рисах».

Ознака ОСОБЛІВІСТЬ, СВОСРІДНІСТЬ презентується через концепт «родзинка», наприклад: «Знайдіть свою Родзинку! Для того щзоб розкрити свій дар, чарівність, прислухайтесь $і$ придивіться до себе. Шукайте й обов'язково знайдете себе!»; «Знайдіть те, щуо виділяє Вас з усіх, прикрашає $i$ захоплює іниих, стиль, який підкреслить те прекрасне, щуо $\epsilon$ в зовнішності. Побудуйте образ навколо власної родзинки, адже в будь-якій зовнішності $\epsilon$ достоїнтвва і недоліки. Зрештою, поняття краси $\epsilon$, $i$ у кожного на цей рахунок власні уподобання. Але будь-якому чоловікові 
подобаються тільки ті жінки, які вміло поєднують внутрішню силу і жіночу слабкість».

Зовнішні ознаки ЧАРІВНОЇ ЛЮДИНИ, які виступають в ролі фізичних «індикаторів» концепту ЧАРІВНІСТЬ в українській мові, пов'язані, перш за все, з мовою тіла: «Покажи свою чарівність за допомогою мови тіла. Мова тіла може багато розповісти про те, наскільки Ви любите себе, і може допомогти Вам здаватися більш відкритим для інших».

Як і в англомовному інтернет-дискурсі, в україномовних текстах-рекомендаціях важливими є наступні ознаки:

(1) мімічні: ОБЛИЧЧЯ (індивідуальне), наприклад: (1) «У будьякому випадку, обов'язково порадьтеся з майстром. Справжні професіонали не тільки врахують індивідуальні особливості обличчя, тип волосся, але й скільки часу у вас може піти на укладання майбутнього шедевра в домашніх умовах». Головним мімічним компонентом є усмішка: красива, щиира, природна, наприклад: «Багато в чому сила жіночої чарівливості в усмішиі. Дуже важливо, щзоб усмішка булу красива, але водночас щиира».

(2) окулесичні: ОЧІ, блиск в очах, ясні, випромінюють, очі як дзеркало душі, наприклад: (1) «Згадайте знайомих вам людей. Ti, у кого очі ясні, блискучі, привертають до себе будь-кого»; (2) «Дивіться прямо в очі співрозмовнику и переконуйте, що у ваших очах $і$ посмішиі написані глибока повага й захоплення ним. 3 часом ви помітите, щзо викликаєте відповідну посмішку $і$ добрий погляд. Це і є чарівність!».

(3) фонаційні: ГОЛОС (привабливий, вібруючій, красивий, глибокий), наприклад: «Якщуо голос привабливо вібрує, багатий нюансами, а рухи тіла м'які, чуттєві - людина має на оточуючих сильний еротичний вплив. І хоча ці фактори часто неусвідомлені, їх цілком можна тренувати».

Частотний розподіл маніпулятивних ознак англійського концепту CHARM загальною кількістю 59 лексичних одиниць на 345 вживань, виявлених методом суцільної вибірки 3 текстіврекомендацій «How to be charming» / або «The ways of charming» загальним об'ємом 15000 словоформ, виглядає наступним чином в ядерній, медіальної і периферійної зонах.

Так, 11 ознак ядерної зони, які найбільш активно використовувалися для навчання, як стати charming person / magnetic 
personality, розподілилися наступним чином в даній підгрупі (загальний обсяг вживання - 179 одиниць / 100\%): (1) smiling $(14,5 \%)$, (2) positive $(10,6 \%)$, (3) genuine $(10,6 \%)$, (4) magnetic $(10,1 \%),(5)$ confident $(10,1 \%),(6)$ engaging $(9,5 \%),(7)$ complimenting $(8,4 \%)$, (8) interesting $(7,3 \%),(9)$ comfortable $(6,7 \%)$, (10) energetic $(6,1 \%),(11)$ warm $(6,1 \%)$.

Медіальну зону ціннісних ознак англійського концепту CHARM склали 37 ознак, які в даній підгрупі розподілилися наступним чином (загальний обсяг вживання - 155 одиниць / 100\%): (1-4) funny, inspirational, open, successful (5,8\%), (5-6) exciting, impressive $(5,2 \%)$, (7) sincere $(4,5 \%)$, (8-9) kind, sharing $(3,9 \%),(10-$ 11) appearance, dynamic, sexual (по 3,2\% кожен), (12-17), intensive, light, (по 2,6\% кожен) та ін.

Периферійну зону ціннісних ознак англійського концепту CHARM склали 11 ознак, кожну 3 яких було в даній вибірці текстів зафіксовано тільки один раз, наприклад, awesome, easy, empathetic, endearing.

Частотний розподіл ціннісних ознак українського концепту ЧАРІВНІСТЬ загальною кількістю 66 лексичних одиниць на 407 вживань, виявлених методом суцільної вибірки 3 текстіврекомендацій «Як бути чарівним» або «Способи, як стати чарівним» загальним об'ємом 15000 словоформ, представлений в такий же спосіб в ядерній, медіальній і периферійній зонах. Так, 10 ознак ядерної зони, які найбільш активно можуть використовуватися для тренувань, як стати чарівною або привабливою людиною, розподілилися наступним чином в даній підгрупі (загальний обсяг вживання - 208 одиниць / 100\%): (1) впевнений $(21,2 \%)$, (2) гарний $(11,1 \%)$, (3) природний $(10,6 \%)$, (4) щирий $(9,6 \%),(5)$ усміхнений $(9,1 \%),(6)$ енергійний $(8,7 \%),(7)$ позитивний $(8,2 \%),(8)$ доглянутий $(7,7 \%),(9)$ справжній $(7,2 \%),(10)$ легкий $(6,7 \%)$.

Медіальну зону склала 41 ознака, розподілені в даній підгрупі наступним чином (загальний обсяг вживання - 189 одиниць / 100\%): (1) веселий, компанійський (по 4,8\%), (2) добрий, красивий, правильний, щасливий, яскравий (по 4,2\%), (3) особливий, охайний $(3,7 \%)(4)$ чуйний $(2,6 \%)$ та ін.

Периферійну зону склали 15 ознак, кожна з яких була в даній вибірці текстів зафіксована тільки один раз, наприклад, 
Ціннісні ознаки кониеепту CHАRM / ЧАРІВНICTБ в англійській...

багатогранний, витончений, врівноважений, загадковий, запальний та ін.

\section{Висновки}

Для англомовних реципієнтів важливою $є$ така ціннісна ознака, як SELF-DEVELOPMENT або DEVELOPMENT OF PERSONALITY / CAMOPOЗВИТОК, яка актуалізується через іiі складові: self-esteem / самоповага, self-confidence / впевненість у собі, self-control/володіння, самовладання, «simply-be-yourself» / «простобудь-собою», що виявляються, у першу чергу, у мові тіла (BODY LANGUAGE), наприклад, FACE (satisfaction, expressive), SMILE (genuine, big, friendly, sincerely), EYE CONTACT (directly), TOUCHING (light), HANDSHAKE (firm), а також VOICE (boldness, confident, gentle, peaceful, direct).

Маніпулятивні ознаки концепту ЧАРІВНІСТЬ у текстахрекомендаціях Інтернет-дискурсу, що використовуються українцями для створення позитивного іміджу у повсякденній комунікації та професійній діяльності, пов'язують 3 цінними ознаками, як-от: душевність, щуирість («щирока душа», «душа компанії»), життєрадісність («иентр тяжіння компанії»), своєрідність («родзинка»), при цьому фізичні характеристики (очі, голос, усмішка) слугують «зовнішніми індикаторами чарівного внутрішнього світу». До прикладу, очі як дзеркало душі, усмішка як генератор позитивних флюїдів тощо.

Доведено, що дискурсивна ознака SELF-DEVELOPMENT англомовного концепту CHARM є контрастною. Установлено, що така дискурсивна ознака українського концепту ЧАРІВНІСТЬ, як СВОСРІДНІСТЬ є контрастними, а дискурсивні ознаки CONFIDENCE і ВПЕВНЕНІСТЬ є інтегральними для двох концептів.

До перспектив даного дослідження зараховуємо подальше вивчення вербалізації концепту CHARM / ЧАРIBHICTЬ в індивідуально-авторських картинах світу, укладання мовленнєвих портретів чарівних лінгвокультурних типажів у неблизькоспоріднених лінгвокультурах.

\section{Література}

Агеичева, О.И. Оценка обаяния телеведущего телезрителями с разными личностными качествами : дисс. ... канд. психол. наук : 19.00.05. Москва, 2007. $227 \mathrm{c}$. 
Карасик, В.И. Языковой круг: личность, концепты, дискурс. Волгоград : Перемена, 2002. $476 \mathrm{c}$.

Карасик, В.И. Языковые ключи. Москва : Гнозис, 2009. 406 с.

Пименова, М.В. Концепт СЕРДЦЕ: Образ. Понятие. Символ. Кемерово : КемГУ, 2007. $500 \mathrm{c}$.

Селіванова, О.О. Сучасна лінгвістика: термінологічна енциклопедія. Полтава : Довкілля-К, 2006. 716 с.

Як стати чарівною і привабливою. [Електронний ресурс]. Режим доступу: http:// megasite.in.ua/110898-yak-stati-charivnoyu-i-privablivoyu.html

Мистецттво чарівності. [Електронний ресурс]. Режим доступу: http://megasite. in.ua/125327-mistectvo-charivnosti.html

Forker, D. (2016). Conceptualization in current approaches of language typology. Acta Linguistica Hafniensia, 48(1), 70-84. DOI: 10.1080/03740463.2016.1176372

Hampton, J., \& Moss, H. (2003). Concepts and meaning: Introduction to the special issue on conceptual representation. Language and Cognitive Processes, 8(5-6), 505-512. DOI: 10.1080/01690960344000161

Müller, E.B. (2012). Charisma - Mit Strategie und Persönlichkeit zum Erfolg: Der Charisma-Code. München : Haufe-Lexware GmbH \& Co. KG.

Ogiermann, E. (2009). On apologising in negative and positive politeness cultures. Amsterdam : Benjamins.

Pinker, St. (2013). Language, cognition, and human nature: selected articles. Oxford : Oxford University Press.

Shipp, N.J., Vallée-Tourangeau, F. \& Anthony, S.H. (2018). Concepts and action: where does the embodiment debate leave us? Psychology of Language and Communication, 22(1), 260-280. DOI: 10.2478/plc-2018-0011

Spencer-Oatey, H. (2008). Culturally speaking: culture, communication and politeness theory. London : Continuum.

Suomela-Salmi, E. (2009). Cross-linguistic and cross-cultural perspectives on academic discourse. Amsterdam : Benjamins.

Taylor, K.I., Devereux, B.J. \& Tyler, L.K. (2011). Conceptual structure: Towards an integrated neurocognitive account. Language and Cognitive Processes, 26(9), 1368-1401. doi: 10.1080/01690965.2011.568227

Be charming. http://www.wikihow.com/Be-Charming

Captivate people. http://www.wikihow.com/Captivate-People

\section{References}

Ageicheva, O.I. (2007). Ocenka obajanija televedushhego telezriteljami s raznymi lichnostnymi kachestvami [The evaluation of charm of an anchorperson by the viewers with different personal qualities]. Extended abstract of candidate's thesis. Moscow [in Russian].

Karasik, V.I. (2002). Jazykovoj krug: lichnost, koncepty, diskurs [Language circle: personality, concepts, discourse]. Volgograd : Peremena [in Russian].

Karasik, V.I. (2009). Jazykovye kljuchi [Language keys]. Moscow : Gnozis [in Russian].

Pimenova, M.V. (2007). Koncept SERDCE: Obraz. Ponjatie. Simvol [Concept HEART: image, notion, symbol]. Kemerovo : KemGU [in Russian].

Selivanova, O.O. (2006). Suchasna linhvistyka: terminolohichna entsyklopediya [Modern linguistics: terminological encyclopedia]. Poltava : Dovkillya-K [in Ukrainian]. 
Yak staty charivnoyu $i$ pryvablyvoyu [How to become charming and attractive]. Retrieved from: http://megasite.in.ua/110898-yak-stati-charivnoyu-i-privablivoyu. html [in Ukrainian].

Mystetstvo charivnosti [The art of being charming]. Retrieved from: http://megasite. in.ua/125327-mistectvo-charivnosti.html

Forker, D. (2016). Conceptualization in current approaches of language typology. Acta Linguistica Hafniensia, 48(1), 70-84. doi: 10.1080/03740463.2016.1176372

Hampton, J., \& Moss, H. (2003). Concepts and meaning: Introduction to the special issue on conceptual representation. Language and Cognitive Processes, 8(5-6), 505-512. doi: 10.1080/01690960344000161

Müller, E.B. (2012). Charisma - Mit Strategie und Persönlichkeit zum Erfolg: Der Charisma-Code. München : Haufe-Lexware GmbH \& Co. KG.

Ogiermann, E. (2009). On apologising in negative and positive politeness cultures. Amsterdam : Benjamins.

Pinker, St. (2013). Language, cognition, and human nature: selected articles. Oxford : Oxford University Press.

Shipp, N.J., Vallée-Tourangeau, F., \& Anthony, S.H. (2018). Concepts and action: where does the embodiment debate leave us? Psychology of Language and Communication, 22(1), 260-280. doi: 10.2478/plc-2018-0011

Spencer-Oatey, H. (2008). Culturally speaking: culture, communication and politeness theory. London : Continuum.

Suomela-Salmi, E. (2009). Cross-linguistic and cross-cultural perspectives on academic discourse. Amsterdam : Benjamins.

Taylor, K.I., Devereux, B.J., \& Tyler, L.K. (2011). Conceptual structure: Towards an integrated neurocognitive account. Language and Cognitive Processes, 26(9), 1368-1401. doi: 10.1080/01690965.2011.568227

Be charming. http://www.wikihow.com/Be-Charming

Captivate people. http://www.wikihow.com/Captivate-People

\section{АНОТАЦІЯ}

Стаття присвячена дослідженню лінгвокультурного концепту CHARM / ЧАРІВНІСТь в англійській та українській мовах. Мета роботи виявити ціннісні характеристики концепту CHARM / ЧАPIBHICTЬ в англомовному та україномовному Інтернет-дискурсах на матеріалі текстів-рекомендацій "Ноw to be Charming» / "Як бути чарівним» та ін. Об'єктом дослідження є концепт CHARM / ЧАРІВНІСТЬ як естетичний компонент англомовної та україномовної картин світу; предметом подібності, відмінності та контрасти в способах вербалізації концепту CHARM / ЧАРІВНІСТЬ в англійській ma українській мовах і специфіка дискурсивного втілення даного концепту у відповідних лінгвокультурах. Проведений аналіз уможливив виділення внутрішніх $і$ зовнішніх ознак формування іміджу CHARMING PERSON / ЧАРІBНА ЛЮДИНА. Внутрішні ціннісні ознаки є змістовними індикаторами концепту CHARM / ЧАРІВНІСТЬ. Зовнішні ціннісні ознаки є фізичними індикаторами концепту і включають мімічні, окулесичні, фоначійні та гаптичні ознаки. Для 
англомовних реципієнтів важливою є така ціннісна ознака, як SELFDEVELOPMENT або DEVELOPMENT OF PERSONALITY / CAMOPOЗBИTOK, яка актуалізується через ії складові: self-esteem/самоповага, selfconfidence / впевненість у собі, self-control / володіння, самовладання, "simply-be-yourself» / "просто-будь-собою», що виявляються, у першу чергу, у мові тіла (ВODY LANGUAGE), наприклад, FACE (satisfaction, expressive), SMILE (genuine, big, friendly, sincerely), EYECONTACT (directly), TOUCHING (light), HANDSHAKE (firm), a mакож VOICE (boldness, confident, gentle, peaceful, direct). Виокремлено такі аксіологічні ознаки концепту ЧАРІВНІСТь в україномовних текстах-рекомендаціях: душевність, щирість («широка душа», «душа компанії), життерадісність («центр тяжіння компанії»), своєрідність («родзинка»), при цьому фізичні характеристики (очі, голос, усмішка) слугують "зовнішніми індикаторами чарівного внутрішнього світу», наприклад, очі як дзеркало душі, усмішка як генератор позитивних флюїдів тощо. Доведено, шо дискурсивна ознака SELF-DEVELOPMENT англомовного концепту CHARM $\epsilon$ контрастною. Установлено, що така дискурсивна ознака українського концепту ЧАРІВНІСТЬ, як СВОЕРІДНІСТЬ є контрастною, а дискурсивні ознаки CONFIDENCE і ВПЕВНЕНІСTЬ є інтегральними для двох концептів.

Ключові слова: концепт, ціннісні ознаки, Інтернет-дискурс, чарівність.

\section{Томчаковская Юлия. Ценностные признаки концепта CHARM / ЧАРІВНІСТЬ в английском и украинском языках (контрастивный аспект)}

\section{АННОТАЦИЯ}

Статья посвящена исследованию лингвокультурного концепта CHARM / ЧАРІВНІСТЬ в английском и украинском языках. Цель работы выявить ценностные характеристики концепта CHARM / ЧАРІВНІСТЬ в англоязычном и украиноязычном Интернет-дискурсах на материале текстов-рекомендаций "Ноw to be Charming" / "Як бути чарівним» и др. Объектом исследования является концепт CHARM / ЧАРІВНІСТЬ как эстетический компонент англоязычной и украиноязычной картин мира; предметом - сходства, различия и контрасты в способах вербализации концепта CHARM / ЧАРІВНІСТЬ в английском и украинском языках и специфика дискурсивного воплощения данного концепта в соответствующих лингвокультурах. Проведенный анализ позволил выделить внутренние и внешние признаки формирования имиджа CHARMING PERSON / ЧАРІВНА ЛЮДИНА. Внутренние ченностные признаки являются содержательными индикаторами концепта CHARM / ЧАРІВНІСТЬ. Внешние ценностные признаки являются физическими индикаторами концепта и включают мимические, окулесические, 
фонационные и гаптические признаки. Для англоязычных реципиентов важна такая ценностная составляющая, как SELF-DEVELOPMENT иЛИ DEVELOPMENT OF PERSONALITY / CAMOPA3BИTИE, которая актуализируется через ее составляющие: self-esteem / самоуважение, self-confidence / уверенность в себе, self-control / самообладание, "simplybe-yourself» / "просто-будь-собой, выявляемых в первую очередь, в языке тела (BODY LANGUAGE), например, FACE (satisfaction, expressive), SMILE (genuine, big, friendly, sincerely), EYE CONTACT (directly), TOUCHING (light), HANDSHAKE (firm), a также VOICE (boldness, confident, gentle, peaceful, direct). Выделены такие аксиологические признаки концепта чАРІВНІСТЬ в украиноязычных текстах-рекомендациях: душевность, искренность («широка душа», "душа компанії»), жизнерадостность («центр тяжіння компанії»), своеобразие («родзинка»), при этом физические характеристики (глаза, голос, улыбка) служат "внешними индикаторами обаятельного внутреннего мира», например, глаза как зеркало души, улыбка как генератор положительных флюидов и тому подобное. Доказано, что дискурсивный признак SELFDEVELOPMENT англоязычного концепта CHARM является контрастным. Установлено, что такой дискурсивный признак украинского концепта ЧАРІВНІСТЬ, как СВОЕОБРАЗИЕ является контрастным, а дискурсивные признаки CONFIDENCE и УВЕРЕННОСТЬ являются интегральными для двух концептов.

Ключевые слова: концепт, ценностные признаки, Интернет-дискурс, charm, очарование. 